\title{
High exposure to Tunga penetrans (Linnaeus, 1758) correlates with intensity of infestation
}

\section{Hermann Feldmeier, Judith D orothea Kehr, Gabriele Poggensee*, Jörg Heukelbach**/+}

\begin{abstract}
Department of Medical Microbiology and Immunology of Infection, Institute of Infection Medicine, Charité-University Medicine Berlin, Germany *Department of Infectious Disease Epidemiology, Robert Koch-Institute, Berlin, Germany **Departmento de Saúde Comunitária, Faculdade de Medicina, Universidade Federal do Ceará e Fundação Mandacaru, Rua Prof. Costa Mendes $1608,5^{\circ}$ andar, 60430-140 Fortaleza, CE, Brasil
\end{abstract}

Tungiasis is a parasitic skin disease widespread in resource-poor urban and rural communities in Brazil. Inhabitants of an urban slum in Northeast Brazil were examined for the presence of tungiasis lesions and followedup twice a week for a period of three weeks. Each time the number, stages, and topographic localization of lesions were recorded on a documentation sheet. The infestation rate (number of newly embedded sand fleas per individual and day) remained stable during the observation period. The infestation rate was significantly related to the intensity of infestation (total number of lesions present) (rho $=0.70, p<0.0001)$ and the proportion of viable lesions $(r h o=0.28, p<0.0001)$. The results indicate that in an endemic area the infestation intensity and the proportion of viable lesions can be used as a proxy to assess the exposure of individuals at risk for tungiasis. Persistently high infestation rates during the transmission season favour the use of prevention measures against invading sand fleas (such as a repellent) rather than a drug to kill already embedded parasites.

Key words: tungiasis - Tunga penetrans - epidemiology - morbidity - Brazil

Tungiasis is a neglected parasitic skin disease of impoverished populations (Heukelbach et al. 2001). The ectoparasitosis occurs in Central and South America, the Caribbean and sub-Saharan Africa (Ade-Serrano \& Ejezie 1981, Arene 1984, Matias 1989, Chadee 1994, 1998, Carvalho et al. 2003). In Brazil it is widespread in urban squatter settlements, villages in the rural hinterland and in traditional fishing communities along the coast (Wilcke et al. 2002, Carvalho et al. 2003).

Community-based studies have consistently shown prevalences between 16 and 55\% in typical endemic areas with a peak of age-specific disease occurrence in children 5 to 14 years and the elderly, and a preponderance of infestation in the male sex (Ade-Serrano \& Ejezie 1981, Arene 1984, Matias 1989, Chadee 1994, Wilcke et al. 2002, Muehlen et al. 2003).

There is a considerable seasonal variation in the intensity of infestation indicating that transmission varies during the year (Heukelbach et al. 2005a). In the semi-arid Northeast Brazil, attack rates decrease as soon as the rainy season begins and re-increase when the weather becomes dryer. Environmental determined patterns in off-host propagation and development of T. penetrans seem to underlie the seasonal variation of attack rates.

In contrast to other ectoparasitoses such as scabies and pediculocis, tungiasis is a self-limiting disease with

Financial support: Komitee Ärzte für die Dritte Welt, Frankfurt (Germany), the DAAD/Capes Probral programme no. 152/ 02 (Germany/Brazil)

+Corresponding author: heukelbach@ufc.br

Received 13 September 2005

Accepted 5 January 2006 duration of four to six weeks (Eisele et al. 2003). As reinfestation is the rule and new lesions may appear close to already embedded fleas, cross-sectional surveys cannot be used to infer on local transmission dynamics. However, anecdotal observations from colonial times suggest that transmission dynamics vary considerably from location to location and that attack rates differ between individuals living in the same area (Karsten 1865, Jolly 1926, Gordon 1941).

In fact, the number of embedded sand fleas per individual varies considerably. Whereas in travellers only a few lesions are observed, individuals in the endemic area may carry several hundred parasites in different stages of development (Bezerra 1994, Mashek et al. 1997, Franck et al. 2003). There is convincing evidence that severe morbidity is the result of a high infestation (Feldmeier et al. 2003).

As a first step towards the assessment and understanding of local transmission dynamics in endemic populations we developed a method to assess the infestation rate (number of newly embedded sand fleas per individual and day) and correlated this measure with infestation intensity (total number of lesions present) and the proportion of viable lesions. The results show that infestation rates remained relatively stable during a period of three weeks and were significantly correlated to the parasite burden and the proportion of viable lesions.

\section{MATERIALS AND METHODS}

The study was conducted in Luxou, Morro do Sandra's and Novo Rumo, three neighbourhoods of the favela Vicente Pinzón, an agglomeration of shantytowns in Fortaleza, the capital of the state of Ceará in Northeast Brazil. The shantytown has a total population of about 15,000 inhabitants, and the three neighbourhoods of 3400 , 1500 , and 4000 , respectively. The three neighbourhoods 
are located on a dune with only a few paved roads. There is one Primary Health Care Centre for the whole favela. The prevalence of the parasitic skin diseases scabies, cutaneous larva migrans, pediculosis, and tungiasis is high (Heukelbach et al. 2003b, 2005a,b). There is no systemic waste collection, public sewage disposal does not exist, and hygiene conditions are precarious. Many stray dogs roam through the favela and rats are seen even at daytime. Unemployment and illiteracy is high, and alcoholism, crime, and domestic violence are important social problems. Sixty percent of the population have a monthly family income of less than two minimum wages (1 minimum wage $\mathrm{H}=100$ Euro) (Family Health Program 1999).

In cooperation with community leaders and members of the neighbourhood associations, households affected by tungiasis were identified. In these households each family member was thoroughly examined for the presence of embedded fleas.

The following findings were considered to be pathognomonic for tungiasis: an itching red-brownish spot with a diameter of 1 to $3 \mathrm{~mm}$, a circular lesion presenting as a white patch with a diameter of 4 to $10 \mathrm{~mm}$ with a central black dot, black crust surrounded by necrotic tissue, as well as partially or totally removed fleas leaving a characteristic sore in the skin (Eisele et al. 2003). Lesions were documented on a visual record sheet. They were counted and staged according to the "Fortaleza Classification" (Eisele et al. 2003), in which stages I to III correspond to viable sand fleas.

Any individual with a minimum of seven embedded fleas (or lesions altered through manipulation) was eligible for the study. Individuals expected not to be regularly at home in the coming three weeks, children less than one year and individuals with severely inflamed lesions were not eligible. The latter were immediately transferred to the next Primary Health Care Centre.

Individuals admitted to the study were examined twice a week from July 17 th to August 11th 2003. Seven points of time of examination were available for the assessment of the infestation intensity (total number of embedded sand fleas) and the proportion of viable lesions, and six observation periods for the determination of the infestation rate (number of newly embedded sand fleas per day of observation).
Individual infestation rates were calculated by dividing the number of newly embedded sand fleas diagnosed at the examination through the person - days of observation, i.e. the number of days having passed since the last examination.

The intra class correlation coefficient (ICC) was calculated to assess the variation of the infestation rate within and between individuals during the study period. The ICC can take a value between +1.0 and -1.0 . The ICC approaches 1.0 when the variation between individuals is very large in relation to the variation within individuals over time and approaches -1.0 when the contrary is the case. Differences of measurements between male and female study members were compared with the Wilcoxon signed rank test. The Spearman rank correlation coefficient was calculated to assess the significance of association between the parameters. Significance calculations were performed with SPSS 11.0 software.

Prior to the studies, meetings with community health workers and community leaders were held and the objectives were explained. Community associations of the township (associações dos moradores) gave their consent to the study. The study protocol was approved by the Ethical Committee of the Federal University of Ceará, Brazil. Informed consent was obtained from all adult participants and from the parents or legal guardians of minors. At the end of the study, all participants and household members with tungiasis were treated twice daily for a period of four weeks with a plant-based repellent which effectively reduces the infestation with T. penetrans (Schwalfenberg et al. 2004).

\section{RESULTS}

Of the 77 subjects included in the study, nine were excluded from data analysis, because they were not encountered in at least one of the six follow-up examinations. Of the remaining 68 individuals, 36 were males and 32 females. Median age was 7.4 years (range 1 to 44 years). The parasitological data stratified by sex are depicted in the Table. The infestation intensity varied from 7 to 144 embedded sand fleas. The infestation rate ranged from 0.8 to 10.75 newly embedded sand fleas per individual and day. It showed a highly skewed distribution with the majority of subjects experiencing one or two new lesions

TABLE

Infestation rate and intensity of infestation during the observation period $(n=68)$.

\begin{tabular}{lcrr}
\hline Parameter & $\begin{array}{c}\text { Median } \\
\text { (interquartile range) }\end{array}$ & Minimum & Maximum \\
\hline Infestation rate ${ }^{a}$ & & & 0.9 \\
$\quad$ Males & $2.4(1.9-3.2)$ & 0.8 & 10.8 \\
$\quad$ Females & $1.7(1.4-2.4)$ & 0.8 & 10.8 \\
$\quad$ Total & $2.0(1.6-2.9)$ & & 149 \\
Intensity of infestation $^{b}$ & & 9 & 118 \\
$\quad$ Males & $34.0(24.8-47.1)$ & 7 & 149 \\
$\quad$ Females & $22.0(16.0-38.3)$ & 7 & \\
$\quad$ Total & $27.3(18.0-40.9)$ & & \\
\hline
\end{tabular}

$a$ : based on the median number of newly penetrated fleas per individual and day at six observations periods; $b$ : based on the median number of total number of lesions present at seven examinations. 
per day (Fig. 1). Neither the infestation rate nor the infestation intensity differed between male and female participants $(\mathrm{p}=0.09$ and $\mathrm{p}=0.19$, respectively).

The infestation rate and the intensity of infestation did not vary considerably during the observation period (Figs 2A, B). An intra class correlation coefficient of 0.19 (95\% CI: $0.02-1.00)$ for the infestation rate indicated that variation within individuals was relatively small as compared to variation between individuals $(\mathrm{p}=0.04)$.

At the beginning of the study $53 \%$ of the lesions consisted of viable sand fleas (stage I to III), $30 \%$ were in stage IV (dead and decaying parasites), and $17 \%$ had been manipulated with a perforating instrument by the patient or his/her carer in an attempt to extract the embedded flea. The proportions did not vary significantly during the observation time and were 59,20 , and $21 \%$, respectively, at the last examination.

Fig. 3A shows that there was a highly significant correlation between the number of newly embedded sand fleas per individual and day and the number of tungiasis lesions present in the respective individual ( $\mathrm{rho}=0.70 ; \mathrm{p}$ $<0.0001)$. A positive correlation was also observed between the infestation rate and the proportion of viable lesions although the correlation coefficient was considerably smaller $($ rho $=0.28 ; \mathrm{p}<0.0001 ;$ Fig. $3 \mathrm{~B})$.

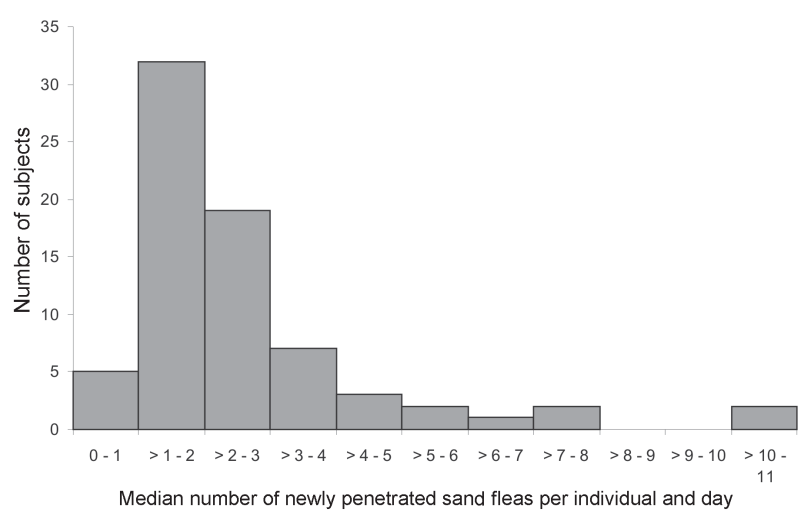

Fig. 1: distribution of infestation rates. Data indicate the medians of the 68 individuals during six observation periods.

\section{DISCUSSION}

Tungiasis occurs in Central and South America, the Caribbean, and sub-Saharan Africa (Heukelbach et al. 2001). Prevalence in the general population may be $50 \%$ and more in the general population and even higher in children and old people (Carvalho et al. 2003, Muehlen et al. 2003, Heukelbach et al. 2005a). The ectoparasitosis is painful, particularly when lesions are located along the nail rim. Pain and itching impede people from sleeping well. In resource-poor settings bacterial superinfection is a constant finding (Feldmeier et al. 2002). Deformation and auto-amputation of digits, deformation and loss of nails, development of chronic ulcers, gangrene, difficulty walking, and gripping (when lesions are located at the hands) are known sequels (Heukelbach et al. 2001).
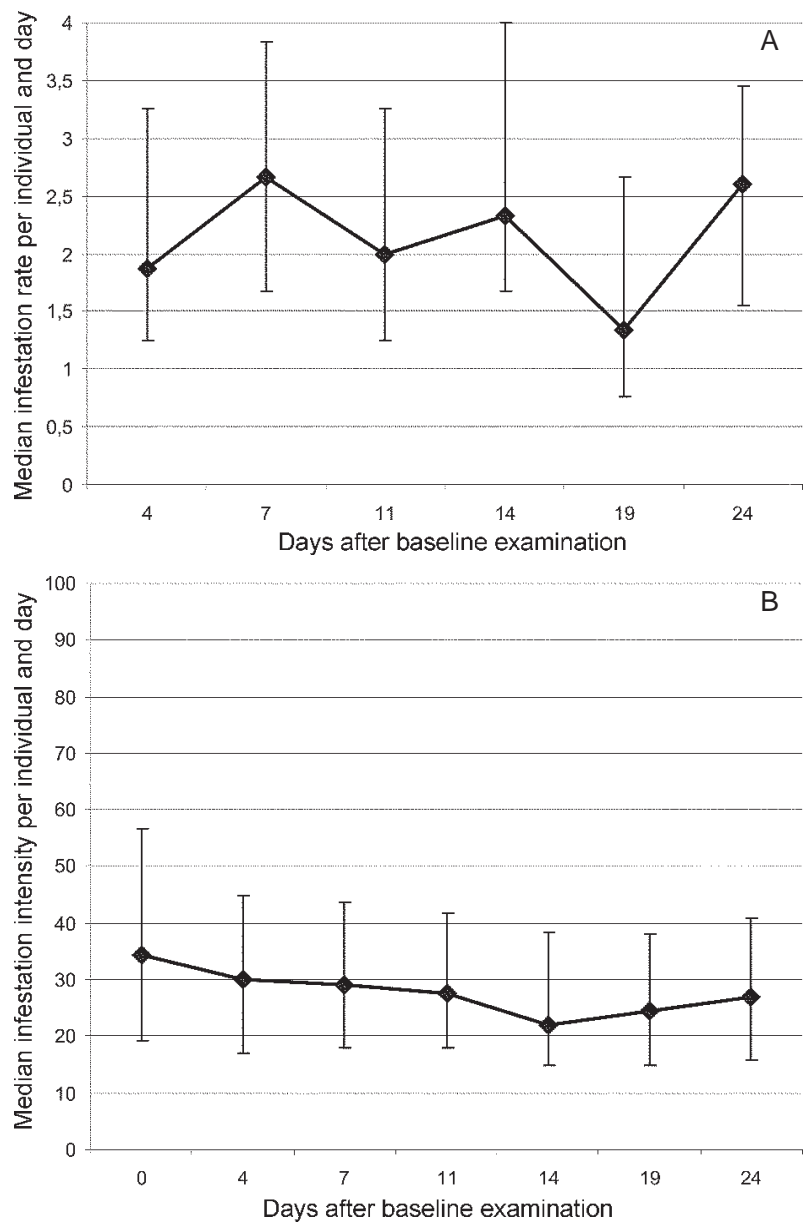

Fig. 2: variation of the infestation rate (A) and the infestation intensity (B) at the different points of observation. Vertical bars indicate interquartile ranges.

Studies performed so far indicate that the ectoparasitosis is unevenly distributed within the community, with a few individuals bearing a high number of embedded sand fleas (Feldmeier et al. 2003, Muehlen et al. 2003). Certain risk factors such as age, type of housing, level of education, and a low socio-economic profile predispose individuals to develop a high intensity of infestation (Muehlen et al. 2005).

The shortcomings of the existing studies are that they are cross-sectional examinations and do not allow to assess to which degree individuals of a community have been exposed. However, the understanding of factors governing local transmission is crucial for the planning of control measures. Precise assessment of transmission would also be helpful in identifying individuals who disproportionably contribute to the spread of the ectoparasites and/or who are most vulnerable for the development of severe disease.

To assess exposure on the individual level we developed a method to determine the number of newly embedded sand fleas in an individual per unit of time. Individuals with tungiasis were carefully examined twice a week. Location of lesions and stages of development were re- 

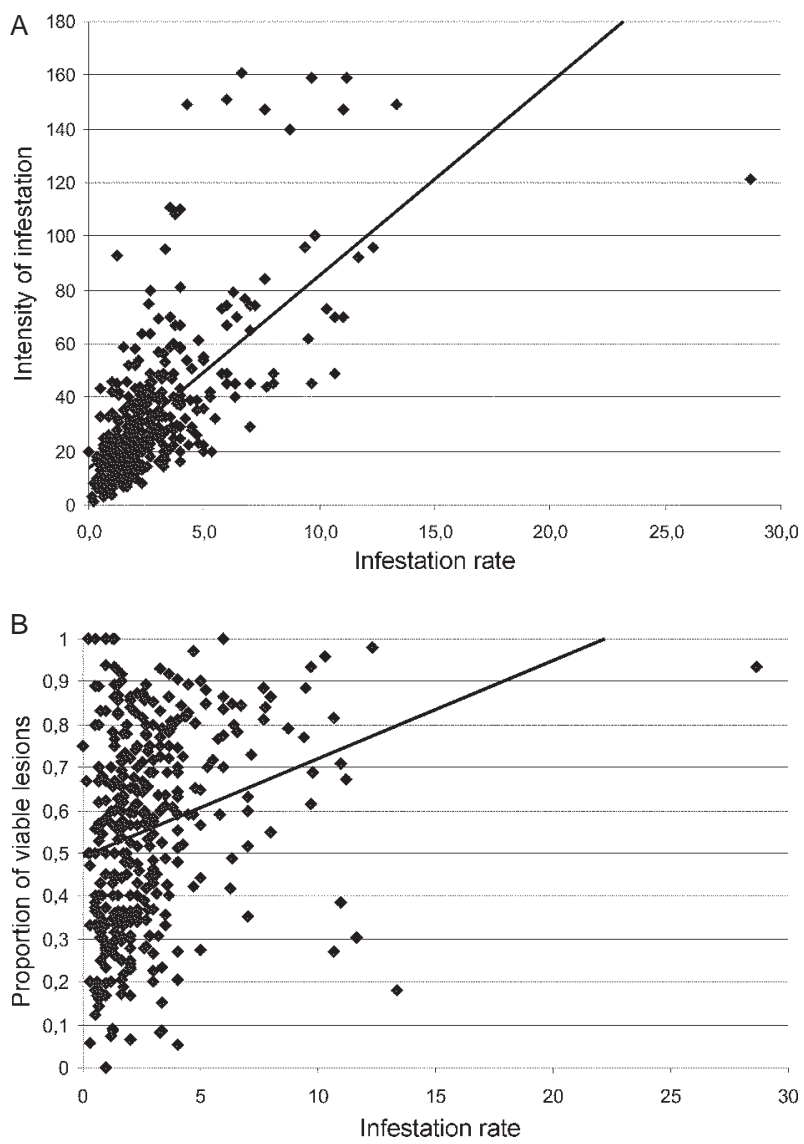

Fig. 3: correlation between the infestation rate and the infestation intensity $(\mathrm{A})(\mathrm{rho}=0.70 ; \mathrm{p}<0.0001)$ and between the infestation rate and the proportion of viable lesions $(\mathrm{B})(\mathrm{rho}=0.28, \mathrm{p}<$ $0.0001)$.

corded on a visual documentation sheet, and newly embedded sand fleas were counted.

The results show that in the group studied on the average each individual experienced two successful penetrations of female $T$. penetrans per day. As supposedly the infestation rate does not vary much during the transmission season of $T$. penetrans in Northeast Brazil, i.e. from May to December, each participant of the study population will experience at least 480 sand flea lesions per year.

To the best of our knowledge, infestation rates have never been determined in parasitic skin diseases. Thus, comparison can only be made with inoculation rates of diseases transmitted by biting insects. For example, in a hyperendemic malaria area the highest inoculation rates (the number of sporozoites of $P$. falciparum transmitted by anopheles mosquitoes per person per year) observed, ranged from 34 to 630 (van der Kolk et al. 2003, Appawu et al. 2004). For other important arthropod-borne infections, these rates are much lower. Although inoculation rates are not directly comparable with the infestation rate used here, it is obvious that the transmission potential of $T$. penetrans is similar to that of $P$. falciparum in a hyperendemic malaria area.
As indicated by an intra class correlation coefficient of 0.2 there was little variation in the infestation rate within affected individuals as compared to variation between individuals. Stable infestation rates during the observation period were confirmed by a similar proportion of viable lesions at the beginning and the end of the study.

There was a highly significant correlation between the infestation rate and the infestation intensity during the study period $($ rho $=0.70, \mathrm{P}<0.001)$. Thus, the infestation intensity can be used as a proxy for the infestation rate. This has practical consequences as the assessment of the infestation rate is laborious, needs repeated examinations and can only be performed by an experienced health worker. In contrast, counting once the total number of lesions can be rapidly performed by an auxiliary, a community health worker or even by the affected individual.

As the infestation rate did not vary considerably in our study and because the development and resolution of sand flea lesions follow a typical time pattern (Eisele et al. 2003), it seemed conceivable that the proportion of viable lesions (stage I to III) observed in an individual at any given point of time also reflects individual exposure. This assumption was confirmed by a highly significant correlation between the infestation rate and the proportion of viable lesions.

The almost constant re-infestation during three weeks of the transmission season is a good argument against chemotherapy. Even if a highly effective compound was at hand, which actually is not the case (Heukelbach et al. 2003a, 2004), it would have to be administered repeatedly in order to kill newly embedded sand fleas. By consequence, in order to keep the parasite load low and the development of morbidity at bay, the use of a repellent seems to be a more rational alternative (Schwalfenberg et al. 2004).

Our study has several limitations. As study participants were selected according to a minimal number of lesions present at baseline, the selection procedure caused a disproportionally high number of moderately to highly infested individuals to be included in the study. Therefore, one cannot infer on the true distribution of infestation rates in the community from these data. Moreover, the correlation between infestation rate and infestation intensity might change, if many individuals with a low infestation rate are included in the regression analysis.

Second, we measured the infestation rate during a period of three weeks. The variation of this measure might be higher if individuals are followed-up for a longer period of time.

In conclusion, our data show for the first time that it is possible to determine the degree of the exposure to $T$. penetrans in individuals of an endemic community. The infestation rate only varied little over time and predicted the number of sand flea lesions present in an individual.

\section{ACKNOWLEDGEMENTS}

To the Associação dos Moradores do Sandra's for supporting the study and to Vania Santos de Andrade and Antonia Valéria Santos de Andrade for skillful assistance. To the secretarial assistance of Michi Feldmeier. JDK received a grant from the Studienstiftung des Deutschen Volkes, Bonn, Germany. The data are part of a medical thesis by JDK. 


\section{REFERENCES}

Ade-Serrano MA, Ejezie GC 1981. Prevalence of tungiasis in Oto-Ijanikin village, Badagry, Lagos State, Nigeria. Ann Trop Med Parasitol 75: 471-472.

Appawu M, Owusu-Agyei S, Dadzie S, Asoala V, Anto F, Koram K, Rogers W, Nkrumah F, Hoffman SL, Fryauff DJ 2004. Malaria transmission dynamics at a site in northern Ghana proposed for testing malaria vaccines. Trop Med Int Health 9: 164-170.

Arene FO 1984. The prevalence of sand flea (Tunga penetrans) among primary and post-primary school pupils in Choba area of the Niger Delta. Public Health 98: 282-283.

Bezerra SM 1994. Tungiasis - an unusual case of severe infestation. Int J Dermatol 33: 725.

Carvalho RW, Almeida AB, Barbosa-Silva SC, Amorim M, Ribeiro PC, Serra-Freire NM 2003. The patterns of tungiasis in Araruama township, state of Rio de Janeiro, Brazil. Mem Inst Oswaldo Cruz 98: 31-36.

Chadee DD 1994. Distribution patterns of Tunga penetrans within a community in Trinidad, West Indies. J Trop Med Hyg 97: 167-170.

Chadee DD 1998. Tungiasis among five communities in southwestern Trinidad, West Indies. Ann Trop Med Parasitol 92: 107-113.

Eisele M, Heukelbach J, van Marck E, Mehlhorn H, Meckes O, Franck S, Feldmeier H 2003. Investigations on the biology, epidemiology, pathology and control of Tunga penetrans in Brazil: I. Natural history of tungiasis in man. Parasitol Res 90: 87-99.

Family Health Program 1999. UBASF Aída Santos e Silva. Relatório de territorialização, Municipal Health Council of Fortaleza, Fortaleza.

Feldmeier H, Eisele M, Saboia-Moura RC, Heukelbach J 2003. Severe tungiasis in underprivileged communities: case series from Brazil. Emerg Infect Dis 9: 949-955.

Feldmeier H, Heukelbach J, Eisele M, Sousa AQ, Barbosa LM, Carvalho CB 2002. Bacterial superinfection in human tungiasis. Trop Med Int Health 7: 559-564.

Franck S, Feldmeier H, Heukelbach J 2003. Tungiasis: more than an exotic nuisance. Travel Medicine and Infectious Diseae 1: $159-166$.

Gordon RM 1941. The jigger flea. Lancet 2: 47-49.

Heukelbach J, de Oliveira FA, Hesse G, Feldmeier H 2001. Tungiasis: a neglected health problem of poor communities. Trop Med Int Health 6: 267-272.

Heukelbach J, Eisele M, Jackson A, Feldmeier H 2003a. Topi- cal treatment of tungiasis: a randomized, controlled trial. Ann Trop Med Parasitol 97: 743-749.

Heukelbach J, Franck S, Feldmeier H 2004. Therapy of tungiasis: a double-blinded randomized controlled trial with oral ivermectin. Mem Inst Oswaldo Cruz 99: 873-876.

Heukelbach J, Wilcke T, Harms G, Feldmeier H 2005a. Seasonal variation of tungiasis in an endemic community. Am J Trop Med Hyg 72: 145-149.

Heukelbach J, Wilcke T, Winter B, Feldmeier H 2005b. Epidemiology and morbidity of scabies and pediculosis capitis in resource-poor communities in northeast Brazil. $\mathrm{Br} J$ Dermatol 153: 150-156.

Heukelbach J, Wilcke T, Meier A, Saboia Moura RC, Feldmeier $\mathrm{H} 2003 \mathrm{~b}$. A longitudinal study on cutaneous larva migrans in an impoverished Brazilian township. Travel Medicine and Infectious Disease 1: 213-218.

Jolly GG 1926. An entomological episode of the East African Campaign. Indian Medical Gazette 61: 164-165.

Karsten H 1865. Beitrag zur Kenntnis des Rhynchoprion penetrans. Virchow's Archiv pathologische Anatomie 32: 269-292.

Mashek H, Licznerski B, Pincus S 1997. Tungiasis in New York. Int J Dermatol 36: 276-278.

Matias RS 1989. Epidemia de tungíase no Rio Grande do Sul. Rev Soc Bras Med Trop 22: 137-142.

Muehlen M, Feldmeier H, Wilcke T, Winter B, Heukelbach J 2005. Identifying risk factors for tungiasis and heavy infestation in a resource-poor community in Northeast Brazil. Trans R Soc Trop Med Hyg. dor: 10.1016/j.physletb.2003. 10.071.

Muehlen M, Heukelbach J, Wilcke T, Winter B, Mehlhorn H, Feldmeier H 2003. Investigations on the biology, epidemiology, pathology and control of Tunga penetrans in Brazil II. Prevalence, parasite load and topographic distribution of lesions in the population of a traditional fishing village. Parasitol Res 90: 449-455.

Schwalfenberg S, Witt LH, Kehr JD, Feldmeier H, Heukelbach J 2004. Prevention of tungiasis using a biological repellent: a small case series. Ann Trop Med Parasitol 98: 89-94.

van der Kolk M, Tebo AE, Nimpaye H, Ndombol DN, Sauerwein RW, Eling WM 2003. Transmission of Plasmodium falciparum in urban Yaounde, Cameroon, is seasonal and age-dependent. Trans R Soc Trop Med Hyg 97: 375-379.

Wilcke T, Heukelbach J, Cesar Saboia MR, Regina SK-P, Feldmeier H 2002. High prevalence of tungiasis in a poor neighbourhood in Fortaleza, Northeast Brazil. Acta Trop 83: 255-258. 